\title{
Violence Directed towards Nurses Working at Al-Medina Hospitals
}

Amar Alsheri ${ }^{1}$, Nayef Almutairi ${ }^{1}$, Alshebli Ahmed $^{1}$

1. Health Sciences College at Al leith, UQU, KSA

\begin{abstract}
Background: According to the recent studies, violence in health care is growing and it excessively affects the retention and recruitment of nurses. It also affects burnout levels and sick leave. Aims: To determine the physical and verbal abuse violence prevalence against nurses in Al-Medina hospitals. Methods: This a descriptive cross sectional study which was conducted in three community hospitals in Saudi Arabia in 2011 using a random sample of 288 nurses. Results: The prevalence of physical violence among the population of the study was $26 \%$. Verbal abuse prevalence was $23.3 \%$. Patients/clients were the major perpetrators of the violence (76.0\%) followed by patient's family member(s) $(24.0 \%)$. Whereas $92.0 \%$ mentioned that the violence action was preventable. Gender was correlated significantly with verbal abuse violence. Conclusion: Our study manifested that the prevalence of physical violence and verbal abuse among nurses at Al-Medina hospitals was high.

Keywords: Violence; Nurses; Hospitals
\end{abstract}

\section{Corresponding author:}

Nayef Almutairi

Health Sciences College at Al leith, UQU, KSA

Email: nff-999@hotmail.com

Receive date: 2017-03-11 | Accept date: 2017-04-22 | Publish date: 2017-05-05

DOI: 10.7575/aiac.abcmed.17.05.03.05

\section{A. I}




\section{Introduction}

Violence is an occupational hazard (DHHS 2002) (1). According to The US National Institute for Occupational Safety and Health (NIOSH) workplace violence is defined as any physical or psychological verbal abuse, threatening behavior or assault happening in an employment place. It includes both covert and overt behaviors ranging from psychological aggression to verbal harassment to bullying and murder (2). Violence in the workplace is a public health, multi-faceted, multicausal, legal and social problem dealing with all occupations all over the world (3-4). Numerous healthcare workers will experience work place violence at least once throughout their professional career. Almost a quarter of the world's work place violence takes place in the health division. workplace violence has been recognized as a main health priority by Public Services International, International Council of Nurses and World Health Organization (5). Violent occurrences have an important long-lasting influence on health care workers. Loss of confidence, anger, lower morale, exhaustion, and time off work, change in job status and disability have been reported (6-7). ICN (8) obviously recognizes the quality care deterioration, erosion from nursing and amplified health costs as the negative results of workplace violence. According to a current study, violence in the setting of health care is rising (9-10). The prevalence of verbal and physical abuse in Hong Kong hospitals was 73\% and $18 \%$ respectively, indicating workplace violence as an important issue against in Hong Kong (11). Origin of the workplace violence can be due to a number of reasons. Individual factors (age, gender, etc.) may increase the risk. Environmental factors (night shifts, inadequate lightning, poor security, etc.) can enhance the risk of being victimized. Excessive workload, understaffing, insufficient working climate, miscommunication and mistrust and numerous other organizational reasons can cause violence in workplaces (12-13). Violence is not only an occupational health problem but also might have major consequences on the quality of care offered (14).

\section{Matrial and Methods}

Design and setting: This descriptive cross sectional research was performed in 2011. The study population included nurses in three of AlMedina hospitals, Saudi Arabia. A total of 288 nurses of the three community hospitals were randomly selected. Two copies of the questionnaire were prepared, one in English and the other in Arabic using translation and back-translation psychometric procedures. Completion of the questionnaire constituted informed consent. Data analysis: The data were analyzed using SPSS 15 . All data are presented in proportions or percentages and means. Statistical comparisons of values between different groups of nurses on their demographical variables were carried out using cross tabs and Chi-square analyses. In all cases a P-value of 0.05 or less was considered significant.

\section{Results}

Table 1 summarizes the characteristics of the informants. Table 2 summarizes the characteristics of physical violence. Table 3 summarizes the relationships between reported physical violence and the characteristics of informants. Table 4 summarizes the characteristics of verbal abuse. Table summarizes the relationship between verbal abuse and the characteristics of informants.

\section{Discussion}

According to findings of the current research, the prevalence of physical violence is $26 \%$ which is higher than what was reported by the study of Mohamed et al. (15). Physical 


\begin{tabular}{lcc}
\hline Variables & Frequency & Percent (\%) \\
\hline Age & & \\
29 and under & 157 & 54.5 \\
$\quad 30-50$ & 109 & 37.9 \\
above 50 & 22 & 7.6 \\
Gender & & \\
Male & 43 & 14.9 \\
Female & 245 & 85.1 \\
Job Main Time & & \\
$\quad$ Full time & 279 & 96.9 \\
$\quad$ Part time & 9 & 3.1 \\
Nationality & & \\
Saudi & 114 & 39.6 \\
Non-Saudi & 178 & 61.8 \\
\hline
\end{tabular}

Table 1: Characteristics of the informants $(n=$ 288)

violence was $16.2 \%$ which was also higher than the result of study conducted by El-Gilany et al. (16) in which violence against main healthcare workers in Al-hassa, Saudi Arabia was studied. About $28 \%$ of the studied population were exposed to at least one violent event throughout the past year. It is also recognized that the physical violence's prevalence in this study is less than the study conducted by Adib et al (17) in Kuwait which repor ted higher prevalence of physical violence $(51.0 \%)$. The results were also higher than Kowk et al. (11) in Hong Kong which reported that violence had been experienced by 320 of 420 nurses (76\%). Aytac et al. showed that workplace violence prevalence is (44.8\%) (18). In addition, a survey done by Nachreiner et al. (19) in Minnesota, U.S showed that the majority of respondents were females (96.0\%) compared to $(67.8 \%)$ in our study. We found that work experience (years) was significantly associated ( $P$ value 0.000) with being exposed to workplace violence and as the number of years of work experience increased, similar findings were gained from a research among U.S. workforce (20). Even though some researches in the literature discovered a contradictory statement that recommends inexperienced and new workers were particularly susceptible to violence (16), Ayranci et al. (21) showed that gender is correlated significantly with physical violence $(P$ value $=0.034)$ and that females are more subjected to violence compared to males. These findings contradict the findings of Aytac et al. (18) in which nearly most of the physical violence's victims were males; while victims of verbal violence were found to be females. The data of the results indicated that nationality is correlated significantly with physical violence $(P$ value $=0.020)$ and nonSaudi nurses are more exposed to physical violence. The result is consistent with findings reported by Adib et al. (17)

\begin{tabular}{lcc}
\hline Variables & Frequency & Percent (\%) \\
\hline $\begin{array}{l}\text { Physical Violence } \\
\text { Yes }\end{array}$ & 75 & 26.0 \\
No & 213 & 74.0 \\
Violence action by? & & \\
Patients / Clients & 57 & 76.0 \\
Family member (s) & 18 & 24.0 \\
Is Violence normal? & & \\
Yes & 13 & 17.3 \\
No & 62 & 82.7 \\
Was the violence action & & \\
preventable? & & \\
Yes & 69 & 92.0 \\
No incidence & 6 & 8.0 \\
Was the & & \\
investigated? & 16 & 21.3 \\
Yes & 4 & 5.3 \\
No & 55 & 73.4 \\
Do not know &
\end{tabular}

Table 2: Characteristics of Physical Violence ( $n=$ 288)

In which it was reported that non-Kuwaiti nurses were more exposed to violence. Patients/clients were reported most frequently as the source of physical violence (76.0\%); this is consistent with previous reports $(22 \%)$ of nurses reported that they were frequently exposed to violent incidents from patients and their relatives (22). In $62.8 \%$ of violence events, patients were the perpetrators; whereas, $16.7 \%$ of events was committed by the relatives. Only $7.4 \%$ of nurses were physically injured due to 


\begin{tabular}{lccc}
\hline \multicolumn{4}{c}{ Prevalence of physical violence } \\
\hline Variables & Yes & No & P value \\
Country of origin & & \\
Saudi & 21 & 93 & 0.020 \\
Non Saudi & 54 & 120 & \\
Gender & & & \\
Male & 6 & 67 & \\
Female & 69 & 176 & \\
Work experience (years) & & 0.000 \\
$\leq 5$ & 30 & 116 & \\
6 - 10 & 31 & 43 & \\
$\geq 11$ & 14 & 39 &
\end{tabular}

Table 3: Relationships between reported physical violence and the characteristics of informants $(n=288)$

violence events in Moustafa et al. study (23). Patients were the major violence perpetrators (54.5\%) and patient's friends/relatives (18.2\%) in Azodo et al. study (24). According to Kwok et al., in all cases the major perpetrators were patients and their relatives. Our study found that $92.0 \%$ of the exposed nurses considered the physical violence events preventable; this was higher than in the study conducted by Moustafa et al. (23) in which only $55.8 \%$ of exposed nurses believed that these events could be prevented.

This study found the prevalence of verbal abuse violence to be $23.3 \%$, which is less than the study conducted to investigate the prevalence of violence against nursing staff in Ismailia governorate, Egypt. In that study, 187 (69.5\%) verbal abuses were reported (23). Relatives of patient/client were reported most frequently as the source of verbal abuse violence $(53.7 \%)$ followed by Patient/client $(25.4 \%)$. The study data showed that gender is correlated significantly with verbal abuse violence $(P$ value $=0.010$ ) and that females are more subjected to violence compared to males.

\begin{tabular}{lll}
\hline Variables & Frequency & Percent (\%) \\
\hline Prevalence of verbal abuse & &
\end{tabular}

$\begin{array}{lcc}\text { Yes } & 67 & 23.3 \\ \text { No } & 221 & 76.7\end{array}$

Frequency of verbal abuse

\begin{tabular}{|c|c|c|}
\hline All the times & & 8 \\
\hline Sometimes & & 57 \\
\hline Once & & 2 \\
\hline $\begin{array}{l}\text { Who verbally } \\
\text { you? }\end{array}$ & abused & \\
\hline Patient/client & & 17 \\
\hline $\begin{array}{l}\text { Relatives of } \\
\text { client }\end{array}$ & patient/ & 36 \\
\hline Staff member & & 13 \\
\hline External & & 1 \\
\hline
\end{tabular}

colleague/worker

Table 4: Characteristics of verbal abuse $(n=$ 288)

\begin{tabular}{lccc}
\hline \multicolumn{4}{c}{$\begin{array}{l}\text { Prevalence } \\
\text { physical violence }\end{array}$} \\
\hline Variables & Yes & No & P value \\
Country of origin & 40 & 74 & 0.000 \\
Saudi & 27 & 147 & \\
Non Saudi & & & \\
Gender & 17 & 26 & 0.010 \\
Male & 50 & 195 & \\
Female & & & \\
Work experience (years) & 106 & 0.039 \\
$\leq 5$ & 40 & 60 & \\
6 - 10 & 14 & 38 & \\
$\geq 11$ & 13 & &
\end{tabular}

Table 5: The relationship between verbal abuse and the characteristics of informants $(n=288)$ 
These results are in line with other studies conducted by Azodo et al. and Adib et al. (24, 17).

\section{Conclusion}

The prevalence of physical violence and verbal abuse among nurses at Al-Medina hospitals was high. Patients/Clients were most frequently the source of physical violence while their relatives were most frequently the source of verbal abuse violence.

\section{Acknowledgment:}

The authors would like to express their deepest gratitude and special thanks to all nurses participated in this study.

\section{References}

1. DHHS (NIOSH) Publication 2002 - 101.Violences: Occupational hazard in hospitals. Washington .DC: National Institute of Occupational Safety and Health. 2002.

2. Chang, E.M., K.M. Hancock, A. Johnson, J. Daly and D. Jackson, 2005. Role stress in nurses: Review of related factors and strategies for moving forward. NursHealth Sci., 7: 57-65

3. Olson NK. Workplace violence: theories of causation and prevention strategies. AAOHN J. 1994; 42(10):477-82.

4. Mayhew C, Chappell D. Workplace violence: an overview of patterns of risk and the emotional/ stress consequences on targets. Int J Law Psychiatry. 2007; 30(4-5):327-39.

5. Hinchberger PA. Violence against female student nurses in the workplace. Nurs Forum. 2009; 44(1):37-46.

6. Levin PF, Hewitt JB, Misner ST. Insights of nurses about assault in hospitalbased emergency departments. Image J Nurs Sch1998; 30:249-54

7. Sullivan C, Yuan C. Workplace assaults on minority health and mental health care workers. Am J Public Health1994; 85:1011-4.

8. International Council of Nurses. 1999. Increasing violence in the workplace is a threat to nursing and the delivery of health care. Press Release. 8 March, Geneva.

9. AlexanderC,FraserJ. Occupationalviolenceinan Australianhealthcaresetting:implicationsformanagers.

JHealthicManag2004;49:377-390;discussion391-372.

10. ItoH, EisenSV, SedererLletal. Factorsaffecting psychiatricnurses

'intentiontoleavetheircurrentjob.Psychiatrserv2001; 52:232-234.

11. Kwok RP, Law YK, Li KE, Ng YC, Cheung MH, Fung VK, et al.: Prevalence of workplace violence against nurses in Hong Kong. Hong Kong Med J. 2006; 12(1): 6-9.

12. Krug EG, Dahlberg LL, Mercy JA, Zwi AB, Lozano R. World report on violence and health. Geneva, Switzerland: WHO; 2002. Retrieved May 24, 2011, from: http://whqlibdoc.who.int/hq/2002/92 41545615.pdf.

13. Spector P, Fox S, Domagalski T. Emotions, violence and counterproductive work behavior. In: Kelloway K, Barling J, Hurrell JJ, editors. Handbook of workplace violence. Thousand Oaks, CA, USA: Sage; 2006. p. 29-46.

14. Arnetz, J. E., \&Arnetz, B. B. (2001). Violence towards health care staff and possible effects on the quality of patient care. Social Science and Medicine, 52, 417-427.

15. Mohamed, A.G., 2002. Work-related assaults on nursing staff in Riyadh, Saudi Arabia. J. Family Community Med., 9: 51-56.

16. El-Gilany AH, EL-Wehady A, Amr M. Violence against primary health care workers in Al-Hassa, Saudi Arabia. J Interpers Violence. 2010;25(4):716-34 (DOI:10.1177 /0886260509334395.

17. Adib, S.M., A.K Al-Shatti, S. Kamal, N. El-Gerges and M. Al-Raqem, 2002. Violence against nurses in healthcare facilities in Kuwait. Int. J. Nurs. Studies, 39: 469-478.

18. Serpil Aytac VeyselBozkurtNuranBayramSelverYildiz Mustafa Aytac. Workplace Violence: A Study of Turkish Workers, International Journal of Occupational Safety and Ergonomics (JOSE) 2011, Vol. 17, No. 4, 385-402.

19. Nachreiner NM, Gerberich SG, Ryan AD, McGovern PM. Minnesota nurses' study; perceptions of violence and the work environment. University of Minnesota, Minneapolis, MN, USA. Health Rep. 2009; 20 (2):7-19.

20. Schat ACH,Frone MR, Kelloway EK. Prevalence of workplace aggression in the U.S. workforce: findings from a national study. In: Kelloway K, Barling J, Hurrell JJ, editors. Handbook of workplace violence Thousand Oaks, CA, USA: Sage; 2006. p. 47-89. 
21. Ayranci U, Yenilmez C, Balci Y, Kaptanoglu C. Identification of violence in Turkish health care settings. J Interpers Violence. 2006; 21:276-96.

22. Madeleine Estryn-Behar, Beatricevander Heijden, Donatella Camerino. Clementine Fry, Olivier Le Nezet, Paul Maurice Conway and Hans-Martin Hasselhorn. Violence risks in nursing-results from the European'NEXT'Study. OccupationalMedicine 2008; 58:107-114.

23. Moustafa A.F. Abbas, Lamiaa A. Fiala, Amira GE. Abdel Rahman, Ayman E. Fahim Epidemiology of Workplace Violence against Nursing Staff in Ismailia Governorate, Egypt. J Egypt Public Health Assoc. 2010; 1\&2:29 - 43.

24. Azodo CC1, Ezeja EB2, Ehikhamenor EE3 Occupational violence against dental professionals in southern Nigeria, African Health Sciences 2011; 11(3): 486 - 492. 